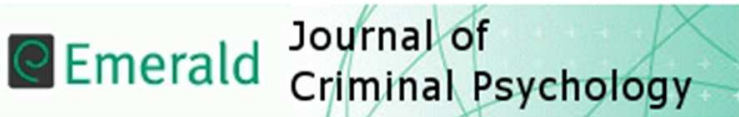

\section{Suicide ideation amongst people referred for mental health assessment in police custody}

\begin{tabular}{|r|l|}
\hline Journal: & Journal of Criminal Psychology \\
\hline Manuscript ID & JCP-04-2016-0016.R1 \\
\hline Manuscript Type: & Research Paper \\
\hline Keywords: & $\begin{array}{l}\text { suicide ideation, police custody, mental health, screening, evaluation, } \\
\text { integration }\end{array}$ \\
\hline \multicolumn{2}{|l}{} \\
\hline
\end{tabular}

SCHOLARONE ${ }^{m}$

Manuscripts 
RUNNING HEAD: Suicide ideation amongst people referred in police custody

\section{Introduction}

The Independent Advisory Panel on Deaths in Custody in England and Wales reviewed all deaths in State custody during the 15-year period 2000 to 2014 and subsequently published this information in a national report (Independent Advisory Panel on Deaths in Custody, 2015). The 8,129 deaths described took place across a wide range of establishments, including prisons, police stations, secure training centres, immigration removal centres, approved premises and hospitals (the latter referring to the deaths of individuals who had mostly been detained in a hospital setting under the terms of the Mental Health Act 1983). Of these deaths, the largest group included people who had been detained under the Mental Health Act 1983 ( $n=4,801,59 \%)$, or who were detained in prison custody at the time of their death $(n=2,727,34 \%)$. Almost a quarter of the total number were self-inflicted $(n=1,921,24 \%)$, and of them the majority $(n=1,572,82 \%)$ were men, while $18 \%(n=349)$ were women. During this same period, there were 355 deaths in police custody, representing $4.4 \%$ of the total number of described deaths (this number having declined from 30 deaths in 2000 to 18 deaths in 2014, after reaching an earlier peak of 39 deaths in 2004 and a low point of 10 deaths in 2012). In 2014, 23\% ( $n=111)$ of all deaths that took place in State custody ( $n$ $=479$ ) were identified as having been self-inflicted (with natural causes identified as the largest single cause of deaths, in $67 \%$ of the total number). Meanwhile, a related national review of selfinflicted deaths in custody of people aged between 18 and 24 reported that during the seven-year period 2007 - 2014, there were 101 deaths in prison custody of people in this age group (Harris, 2015).

Within the general community, there were 6,233 suicides in the UK in 2013 . The highest suicide rates were amongst people aged in their forties, with 2013 having the highest reported rate of male suicide since 2001 (Samaritans, 2015). The rate amongst men was 19 per 100,000 deaths, compared with 5.1 per 100,000 deaths amongst women, and "hanging, strangulation and suffocation" were reportedly the most common methods used (Office of National Statistics, 2015). Meanwhile, suicide rates in the criminal justice system are known to exceed those in the community, with rates in prisons having been described as up to six times higher than community samples (Fazel, Gran, Kling \& Hawton, 2011). People who have just been released from prison 
RUNNING HEAD: Suicide ideation amongst people referred in police custody present an increased risk of suicide when compared with the general population (Pratt, Piper, Appleby, Webb \& Shaw, 2006), with significantly associated factors including histories of self-harm, alcohol misuse, mental health diagnosis, increasing age over 25 , being released from a local prison, and requiring community mental heatlh team follow-up (Pratt, Appleby, Piper, Webb \& Shaw, 2010). A recent population-based nested case-control study found that $13 \%$ of suicides in the general population had accessed community justice pathways in the period before their deaths (King, Senior, Webb, Millar, Piper, Pearsall, Humber, Appleby \& Shaw, 2015). In another matched cased-control study, recent involvement at court was a factor in almost a third of people who died by suicide (Cook \& Davis, 2012), confirming earlier work demonstrating increased vulnerability to suicide and self-inflicted death amongst people in prison and offenders in community settings (McKenzie, Borrill \& Dewart, 2013; Sattar, 2001). Self-harming behaviour is also more common in prisons, with such incidents being recorded in up to $6 \%$ of male prisoners and $24 \%$ of female prisoners every year, and a demonstrable link between acts of self-harm and subsequent completed suicide (Hawton, Linsell, Adeniji, Sariaslan \& Fazel, 2014). In addition, high rates of suicide ideation persist amongst people in the criminal justice system, with reports describing a prevalence of suicide ideation of $41 \%$ amongst a community corrections sample (Gunter, Chibnall, Antoniak, Philibert \& Hollenbeck, 2011), and a lifetime prevalence of up to a third in a random stratified sample of 996 people in prison (Larney, Topp, Indig, O’Driscoll \& Greenberg, 2012).

The increased risk of suicide presented by people who are in contact with all stages of the criminal justice system is formally recognised within the national suicide prevention strategy for England (Department of Health, 2012). However, it is vital to understand that these risk factors are not fixed, and therefore to enable staff to use tools to intervene and share their concerns widely when risk arises (Prisons and Probation Ombudsman for England and Wales, 2014). In order to reduce the high numbers of deaths within prisons in England and Wales, initiatives aimed at wider systems improvements have been under-pinned by the central idea that Suicide is Everyone's Concern for the last 17 years (Her Majesty's Inspectorate of Prisons, 1999). This concept has been translated into operational service delivery through the Assessment, Care in Custody and Teamwork (ACCT) system, a nationally prescribed and centrally co-ordinated care-planning system that requires all staff who come into contact with prisoners to be trained, and which sets 
RUNNING HEAD: Suicide ideation amongst people referred in police custody minimum standards for the support and engagement of people who are thought to be at risk (Ministry of Justice, 2013). This model finds fairly broad support in the literature (Forrester \& Slade, 2014) and more recently further evidence has started to emerge in support of models that ensure the engagement and co-operation of representatives of multiple agencies across health and justice areas, with the joint aim of custodial suicide prevention (Slade \& Forrester, 2015).

By contrast, operational responses in police custody sit within the framework provided by the Police and Criminal Evidence Act 1984. This Act outlines the powers of the police and it has a major impact on the delivery of healthcare services in police custody. It has a broad remit that includes arrest procedures, general arrangements for detention, and the questioning and treatment of people by police officers. In accordance with the Act, "a person shall not be kept in police detention for more than 24 hours without being charged", a necessary limitation to detention which also impacts upon healthcare assessments. Arrangements for the care and treatment of detained people are set out in the code of practice that accompanies the Act: in considering these "the custody officer must make sure a detainee receives appropriate clinical attention as soon as reasonably practicable" if they are suffering from physical or mental health problems, or if they require clinical attention (Home Office, 2014). Protection is meant to be offered to adults who have been identified as mentally vulnerable during their detention and questioning, through the appropriate adult service (National Appropriate Adult Network, 2013). Additionally, as part of their further powers, Section 136 of the Mental Health Act 1983 allows police officers to take a person "who appears to him to be suffering from mental disorder and to be in immediate need of care or control" to a place of safety, where further mental health assessments can then be arranged.

These operational responses are, in part, designed to enable services to deal with the high levels of morbidity (including mental and physical health problems, and substance misuse) that have been well-described in the police-custody healthcare literature (Ceelen, Dorn, Buster, Stirbu, Donker \& Das, 2012; Payne-James, Green, Green, McLachlan, Munro \& Moore, 2010; McKinnon \& Grubin, 2010). Alongside these high levels of morbidity are some reports of high levels of suicide ideation amongst detained people, with up to half of these individuals being missed by existing police screens despite the known importance of early and effective screening (Noga, Walsh, Shaw \& Senior, 2015; Noga, Foreman, Walsh, Shaw \& Senior, 2015; McKinnon \& Grubin, 2013). Yet 
RUNNING HEAD: Suicide ideation amongst people referred in police custody despite these high reported levels of suicide ideation, there have been relatively few studies examining those who present with suicide ideation in police custody. By contrast, we understand much more about suicide risk in prison settings (Felthous, 2011), including which prisoners are at highest risk, and when in the process of imprisonment this risk is greatest (Forrester \& Slade, 2014; Felthous, 2011). However, because the literature regarding suicide ideation and self-harming behaviour is more developed in prison settings than in police custody or courts, and given some of the commonalities that exist across the different parts of the criminal justice system pathway, this same literature is generally also co-opted to assist in understanding these issues as they arise in police custody. As the links between self-harming behaviour and completed suicide are progressively understood, (Hawton, Linsell, Adeniji, Sariaslan \& Fazel, 2014), the role of earlier trauma in cases of completed suicide is also increasingly identified (Oakes-Rogers \& Slade, 2015). In addition, examinations of people in prison who have survived serious suicide attempts have assisted wider understanding of the psychological processes involved. In male prisoners, for example, adverse events such as relationships coming to an end, or bereavement, are known to be important factors (Rivlin, Fazel, Marzano, \& Hawton, 2011). Mental health concerns (such as substance withdrawal and psychiatric symptoms) and issues related to sentencing are also described, with many of these individuals having also describing suicidal intentions and visual images relating to suicide in the period before a suicide attempt (Rivlin, Fazel, Marzano, \& Hawton, 2011). In female prisoners, hopelessness and impulsivity have been described as important factors, and a background of repeated suicide attempts, and suicide ideation, is often present (Marzano, Fazel, Rivlin, \& Hawton, 2011).

Within this context, and recognising the general paucity of literature in the particular area of suicide ideation in police custody settings, this project aimed to examine the prevalence of suicide ideation amongst a group of people who had been arrested and taken into police custody, and were then referred to a mental health service operating in the police stations. It also aimed to describe any features that were associated with these suicidal ideas across a range of domains (including clinical factors such as self harm and suicide attempt history, current diagnostic categorisation, mental health history and current substance use, and offending and service factors such as offending behaviour and criminal justice system experience and service response). It also 
RUNNING HEAD: Suicide ideation amongst people referred in police custody aimed to consider whether any recommendations could improve healthcare service delivery in this area.

\section{Method (aim for 775 words)}

\section{Setting}

The sample was collected as part of an evaluation of a mental health service operating across two police stations in one borough of south London. The service was funded by a grant provided by Guy's and St Thomas' Charity and the service was provided by the local National Health Service (NHS) Mental Health Trust. The service was physically located in the police stations, where referrals were received and assessments were undertaken by nursing staff who were employed by the mental health service.

\section{Sample}

A sample of 888 cases from a consecutive referred sample had sufficient data for which comparative analysis could be undertaken. These cases were collected over an 18-month period during 2012 and 2013, and of this group 144 (16.2\%) reported current suicide ideation in police custody. There were 174 women and 709 men in the sample (of whom, respectively, $20.1 \%$ and $15.1 \%$ reported current suicide ideation), although the gender of 5 cases was not recorded. The age range for the suicide ideation group range from $19-72$ years $(M=35.2$ years, $S D=9.6)$ and for the non-suicide ideation group the age ranged from 18-79 years $(M=35.3, S D=9.6)$.

\section{Procedures}

As highlighted in the introduction, police powers and procedures in respect of arrest and subsequent detention in custody are set out in the Police and Criminal Evidence Act 1984. The terms of this Act allow police constables to arrest people in respect of whom there is reasonable suspicion that they are about to commit, are in the act of committing, or have committed an offence. After being arrested and brought into police custody, the police must charge a person within 24-hours (or apply for a longer period of detention of 36 or 96 hours in cases where the crime is thought to be sufficiently serious). During this time, the police are obliged to follow a number of processes that are meant to protect the rights of individuals, these processes being set out in relevant codes of practice (Home Office, 2014). As part of the initial process, custody sergeants apply a nationally agreed basic health screen - although this same screen, which is 
RUNNING HEAD: Suicide ideation amongst people referred in police custody presently in use throughout England and Wales, has been shown to be inadequate at assessing for the presence of a range of healthcare problems (including physical health problems such as head injuries and alcohol withdrawal, and mental health problems including suicide risk) (McKinnon \& Grubin, 2014).

In the current study, after the basic health screen had been applied, detainees could then be referred on for further physical healthcare (e.g. to a primary care nurse, or a Forensic Medical Examiner - i.e. a primary care doctor) if this was considered useful or appropriate. Detainees could also be referred to the mental health service at any stage in the process, either directly by the custody sergeant, or after they had initially been reviewed by a primary care clinician (this referral mechanism having been introduced by the mental health service in order to ensure that a service would be offered to as many people as possible, in recognition of the high morbidity levels that had been anticipated).

After a referral was made, the mental health service then sought to assess all referred detainees within a four-hour period (this target being deliberately in keeping with targets for acute care assessment elsewhere in the National Health Service). A clinical assessment was conducted using a template in which background information was collected (including information about their previous clinical history, substance misuse, alleged offence, any pre-identified diagnoses, and the response of the service). All of this information was collected as part of the standard operating procedure of the service. The collected information was then entered into an anonymous database on a weekly basis and presented for further analysis using a statistical software package.

Following an assessment, all available information was synthesised to enable a clinical decision regarding the most suitable onward pathway. In cases where there was thought to be a risk of suicide (i.e. cases in which suicide ideation had been disclosed), consent was sought to share this information with other agencies.

\section{Data analysis}

All analyses were performed using SPSS version 22 (IBM Corp, 2013). In order to compare police custody detainees who reported suicide ideation with those who did not, a series of Chisquare analyses were undertaken. Post-hoc power analysis confirmed that $90 \%$ power to detect a 
RUNNING HEAD: Suicide ideation amongst people referred in police custody large effect size (>.50) was achieved with the sample size, with an X2 value greater than 2.7. All variables which had fewer than five cases in each cell were removed from the analysis.

\section{Ethical considerations}

Appropriate approval for this evaluation was obtained from the relevant body within the local National Health Service organisation.

\section{Results}

\section{Socio-demographic factors}

No significant differences were recorded for the suicide ideation sample compared to the non-suicide ideation sample across a range of variables, including: their employment (13 vs $17 \%$ ); whether they were receiving benefits ( 67 vs $68 \%$ ); whether they had children ( $44 \%$ vs $38 \%$ ); whether they were homeless ( $12 \%$ vs $8 \%$ ); and whether they were married or cohabiting (12 vs $13 \%)$.

There were no significant differences for most ethnic groups, apart from Mixed heritage arrestees who were over-represented in the suicide ideation sub-group. The ethnic categories for the sample, by suicidal ideation group (i.e. suicide ideation and no suicide ideation), are reported in Table 1 below:

\section{${ }^{* * *}$ Insert Table 1 here ${ }^{* * *}$}

As outlined in Table 2, the suicide ideation group were also more likely to have English as their first language.

\section{Clinical factors}

Self harm and suicide attempt history. The analyses confirmed that arrestees reporting suicide ideation were more likely to have a history of self-harm, or a suicide attempt, with $82.6 \%$ of the suicide ideation sample disclosing both previous harmful behaviours.

Current diagnostic categorisation. In relation to identified diagnostic category, people with suicide ideation were under-represented amongst those with schizophrenia or psychosis, and over-represented amongst the depression, post traumatic stress disorder (PTSD) and personality disorder categories. There were no significant differences between groups regarding the likelihood of substance use disorders or intellectual disability. 
RUNNING HEAD: Suicide ideation amongst people referred in police custody

Mental health history. The group presenting with suicidal ideas were more likely to have previously been known to mental health services, to have a previous mental disorder, and to be in receipt of psychotropic medication. There was no significant difference in the likelihood of prior admission to psychiatric hospital.

Current substance use. The suicide ideation group were more likely to have consumed alcohol or drugs in the 24 hours before they were brought into police custody, with a history of alcohol consumption being most likely. The reported numbers for all other substances (apart from cannabis use) within the suicide ideation group were too low $(<5)$ for further analysis.

\section{Offending and service factors}

Offending behaviour and criminal justice system experience. There were no significant differences in alleged offences, or in having a previous violent conviction, between the groups. However, the suicide ideation sub-group was more likely to have been on bail when arrested.

Service response. The suicide ideation sub-group was more likely to be seen by a health professional in the police station. There was no significant difference in whether they were considered fit for interview.

\section{${ }^{* * *}$ Insert table 2 here ${ }^{* * *}$ \\ Discussion}

In this study we aimed to examine the prevalence of suicide ideation amongst people in police custody who were referred to a mental health service operating in the police stations. Our secondary aims were to describe any features that were associated with this suicide ideation, and to consider what could be learned to improve healthcare service delivery in police custody.

Overall, a substantial number from this referred sample reported suicide ideation during their time in police custody $(144 ; 16.2 \%)$. with women reporting a greater proportion of suicidal ideas than men. Yet although these high reported levels of suicidal ideas are concerning, they are broadly consistent with results that have been reported in the wider literature. One group described suicidal ideas in $10.5 \%$ of a sample of 237 detainees (McKinnon, Srivastava, Kaler \& Grubin, 2013), while another described a history of self-harming behaviour in $54 \%$ of women who were referred to a mental health service operating in police custody (Scott, McGilloway \& Donnelly, 2009). The results are also in keeping with research findings from the lower (Magistrates') courts, 
RUNNING HEAD: Suicide ideation amongst people referred in police custody suggesting that the effect may operate across the whole criminal justice pathway, rather than merely in one part of it (Shaw, Creed, Price, Huxley \& Tomenson, 1999). These results also compare with reports from the general population for all suicidal ideation of between 1.1 and $19.8 \%$ (Casey, Dunn, Kelly, Lehtinen, Dalgard, Dowrick \& Ayuso-Mateos, 2008) and with research demonstrating that $13 \%$ of all suicides taking place in the general population had been inside the criminal justice pathway in the period before their death (King, Senior, Webb, Millar, Piper, Pearsall, Humber, Appleby \& Shaw, 2015). The higher levels of suicide ideation amongst women are also consistent with our existing understanding, and with resulting policy initiatives in this area (Corston, 2007). The fact that people who reported suicide ideation were more likely to have a history of self-harm, or a prior suicide attempt, indicates a group in which a persistence of vulnerabilities contributes to their risk in police custody. The results are stark, with $82.6 \%$ of the suicide ideation sample reporting both prior harmful behaviours. It suggests that some of the risk in police custody is imported from the community, rather than merely arising as a consequence of detention. However, it should be understood within the context of our existing understanding that those with the greatest level of vulnerability have higher levels of mental distress in police custody (Baksheev, Thomas \& Ogloff, 2012). The over-representation of suicide ideation amongst those from particular diagnostic categories (depression, post-traumatic stress disorder and personality disorder) is also consistent with this model, and with our understanding of the psychopathology associated with these conditions (Hawton \& James, 2005; Harris \& Barraclough, 1997). Taken as a whole, these finding provide support for calls for improved screening, with the aim of improved diagnostic precision amongst all police custody detainees (McKinnon \& Grubin, 2014).

The over-representation of suicide ideation amongst those who have a history of mental disorder, who are already known to mental health services, and who are already taking medication, supports the idea that contact with the criminal justice system can occur at times of crisis. It is known, for example, that some people are more likely to come into contact with the criminal justice system as their mental state deteriorates during a first psychotic episode (Bhui, Ullrich, Kallis \& Coid, 2015). The presence of these high levels of distress, and their association with underlying established mental disorder, makes a further case for the liaison and diversion services that are currently being piloted across England and Wales with a view to wider introduction (Bradley, 2009; 
RUNNING HEAD: Suicide ideation amongst people referred in police custody

Srivastava, Forrester, Davies \& Nadkarni, 2013). It also, however, raises questions about the extent to which the support and treatment that is meant to be provided by community mental health services operating within the National Health Service (NHS) has a wider role in the prevention of offending behaviour (Independent Mental Health Taskforce, 2016), recognising the role that mental illness plays here alongside other criminogenic factors (Ministry of Justice, 2013).

Within this sample, there was a clear association between suicide ideation and the use of alcohol and drugs in the 24-hour period before arrest. Within the wider literature, alcohol dependence in particular is known to be associated with suicidal behaviour, and there is also emerging understanding of the adverse role that acute intoxication can play (Kaplan, McFarland, Huguet, Conner, Caetano, Giesbrecht \& Nolte, 2012). This indicates the need for a robust service response within both primary care and mental health services in police custody, and, possibly, for a renewed strategy for approaching those who are intoxicated while they are in police custody. Brief screening and interventions, for example, are thought to be feasible in this setting (Chariot, Lepresle, Lefevre, Boraud, Barthes \& Tedlaouti, 2014), and there is some evidence that an improved strategy for managing intoxicated people in police custody can lead to safety improvements (Aasebo, Orskaug \& Erikssen, 2016).

As regards service response, it is encouraging to note that the suicide-ideation sub-group was more likely to have been seen by an arrest referral worker, or another health professional, prior to their mental health assessment. It indicates that this service was successfully identifying people at greatest risk, in keeping the stated policy aim of assessing people as early in the process of their detention as possible (Bradley, 2009). It also provides evidence for the integrated working that it thought to be particularly necessary in this field (Till, Exworthy \& Forrester), and it suggests that a degree of co-operation is in fact occurring at ground level, despite a lack of join-up in the service commissioning process (Forrester, Valmaggia \& Taylor, 2016). Within this study, information regarding suicide risk was used in individual cases to plan onward care and management and consent was requested to share this information with other agencies to assist in keeping the individual safe. Although code C of the Police and Criminal Evidence Act 1984 clearly sets out how mentally disordered or otherwise vulnerable people in custody should be managed, there is little specific guidance regarding the management people with suicide ideation. Further, 
RUNNING HEAD: Suicide ideation amongst people referred in police custody given established difficulties in transferring risk information across criminal justice system pathways (Roberts, Senior, Hayes, Stevenson \& Shaw, 2011) there is a need for further research to understand how and where this works best to enable systemic improvement. However, given the necessity for close multi-agency cooperation in managing risk (Prisons and Probation Ombudsman for England and Wales), it would seem sensible to consider a future in which a joint vehicle for risk management, similar to the ACCT process in design, is piloted and reviewed, with a view to its establishment across the whole criminal justice pathway.

This evaluation has a number of strengths and weaknesses. As regards the former, the sample evaluated is larger than those described elsewhere in the literature, and it adds some new evaluation findings to the relatively small existing number of papers in this particular field. Further, in offering an evaluation of a real service operating in police custody, it provides a ground level view that could assist with the development of other similar services. In particular, it provides useful information regarding the identified suicide ideation sub-group, including their associated characteristics. As regards weaknesses, this evaluation took place in only one service, and its results may be geographically limited. Further, although a number of variables were collected, diagnostic instruments could not be used because the service operated a clinical priority within considerable time constraints. Although the service assessed those who were referred to it, many other individuals were received into police custody who were not referred, and the extent to which this un-assessed group also presented with suicide ideation is unknown.

The results of this evaluation provide support for a number of recommendations. The first of these is for improved diagnostic screening within these services as standard - including screening for a history of self-harming behaviour, previous suicide attempts, and history of mental health problems. This recommendation already finds support elsewhere in the literature (Noga, Walsh, Shaw \& Senior, 2014; McKinnon \& Grubin, 2013). The second recommendation is to review safety improvements for those who have recently used drugs or alcohol, building on results elsewhere that have described safety improvements with this group (Aaesebo, Orskaug \& Erikssen, 2016). The third recommendation is for further research in this area to better understand the link between suicide ideation in police custody and self-harm or suicide within in the criminal justice pathway, or after leaving it. The wider field of suicide prevention is one in which there is a recognised paucity of 
RUNNING HEAD: Suicide ideation amongst people referred in police custody

randomised controlled trials (Zalsman, Hawton, Wasserman et al., 2016), but given the high

proportion of deaths by suicide within criminal justice pathways (King, Senior, Webb et al., 2015),

there is a strong argument for a specific research focus in this area that is marked by its

vulnerability. The fourth recommendation is to ensure optimal integration between mental health,

substance misuse and physical health services within police custody (as is the aim across the

whole criminal justice pathway), obviating the need for referrals between different services (Till,

Exworthy \& Forrester, 2014). This last recommendation, while progressive and aspiration in its

intention, also recognises that limitations exist within current commissioning and funding

arrangements (Forrester, Valmaggia \& Taylor, 2016). Nonetheless, given the apparent value of

multi-agency collaboration in reducing risk (Prison and Probation Ombudsman for England and

Wales), a joint vehicle to enable risk management across the entire criminal justice pathway would

now be a useful approach to pilot.

\section{References:}

Aasebo, W., Orskaug, G., \& Erikssen, J. (2016). Can deaths in police cells be prevented? Experience from Norway and death rates in other countries. Journal of Forensic and Legal Medicine, 37, 61-65.

Baksheev, G., Thomas, S., \& Ogloff, J. (2012). Psychopathology in police custody: the role of importation, deprivation and interaction models. International Journal of Forensic Mental Health, 11(1), 24-32.

Bhui, K., Ullrich, S., Kallis, C., \& Coid, J. (2015). Criminal justice pathways to psychiatric care for psychosis. The British Journal of Psychiatry, 207(6), 523-529.

Bradley, K. (2009). The Bradley Report: Lord Bradley's review of people with mental health problems or learning disabilities in the criminal justice system. London: Department of Health.

Casey, P., Dunn, G., Kelly, B., Lehtinen, V., Dalgard, O., Dowrick, C., \& Ayuso-Mateos, J. (2009). The prevalence of suicidal ideation in the general population: results from the outcome of Depression International Network (ODIN) study. Social Psychiatry and Psychiatric Epidemiology, 43(4), 299-304.

Ceelen, M., Dorn, T., Buster, M., Stirbu, I., Donker, G., \& Das, K. (2012). Health-care issues and health-care use among detainees in police custody. Journal of Forensic and Legal Medicine, 19(6), 324-331.

Chariot, P., Lepresle, A., Lefevre, T., Boraud, C., Barthes, A., Tedlaouti, M. (2014). Alcohol and substance screening and brief intervention for detainees kept in police custody. A feasibility study. Drug and Alcohol Dependence, 134(1), 235-241.

Cook, T., \& Davis, M. (2012). Assessing legal strains and risk of suicide using archived court data. Suicide and Life Threatening Behaviour, 42(5), 495-506. 
RUNNING HEAD: Suicide ideation amongst people referred in police custody

Corston, J. (2007). The Corston Report: A Report of a Review of Women with Particular Vulnerabilities in the Criminal Justice System. London: Home Office.

Fazel, S., Grann, M., Kling, B., \& Hawton, K. (2011). Prison suicide in 12 countries: an ecological study of 861 suicides during 2003 - 2007. Social Psychiatry and Psychiatric Epidemiology, 46(3), 191-195.

Felthous, A. (2011). Suicide behind bars: trends, inconsistencies and practical implications. Journal of Forensic Science, 56, 1541 - 1555.

Forrester, A., \& Slade, K. (2014). Preventing self-harm and suicide in prisoners: job half done. The Lancet, 383(9923), 1109-1111.

Forrester, A., Valmaggia, L., \& Taylor, P. (in press). Healthcare services in police custody in England and Wales. British Medical Journal.

Harris, E. C., \& Barraclough, B. (1997). Suicide as an outcome for mental disorders. A metaanalysis. The British Journal of Psychiatry, 170(3), 205-228.

Harris, T. (2015). Changing prisons, saving lives: report of the Independent Review into selfinflicted deaths in custody of 18-24 year olds. London: Ministry of Justice.

Hawton, K., \& James, A. (2005). Suicide and deliberate self harm in young people. BMJ, 330(7496), 891-894.

Hawton, K., Linsell, L., Adeniji, T., Sariaslan, A., \& Fazel, S. (2014). Self-harm in prisons in England and Wales: an epidemiological study of prevalence, risk factors, clustering, and subsequent suicide. The Lancet, 383(9923), 1147-1154.

Her Majesty's Inspectorate of Prisons for England and Wales. (1999). Suicide is everyone's concern: a thematic review. London: HMIP.

Home Office. (2014). Revised code of practice for the detention, treatment and questioning of persons by police officers: Police and Criminal Evidence Act 1984 (PACE) - Code C. London: Home Office.

IBM Corp. Released 2013. IBM SPSS Statistics for Windows, Version 22.0. Armonk, NY: IBM Corp.

Independent Advisory Panel on Deaths in Custody. (2015). An examination of the cases 2000 to 2014. London: Independent Advisory Panel on Deaths in Custody.

Independent Mental Health Taskforce. (2016). The five year forward view for mental health. London: NHS England.

Kaplan, M., McFarland, B., Huguet, N., Conner, K., Caetano, R., Giesbrecht, N., \& Nolte, K. (2012). Acute alcohol intoxication and suicide: a gender-stratified analysis of the national violent death reporting system. Injury Prevention, 19, 38-43.

King, C., Senior, J., Webb, R., Millar, T., Piper, M., Pearsall, A., Humber, N., Appleby, L., \& Shaw, J. (2015). Suicide by people in a community justice pathway: population-based nested case-control study. The British Journal of Psychiatry, 206, 1-2.

Larney, S., Topp, L., Indig, D., O'Driscoll, C., \& Greenberg, D. (2012). A cross-sectional survey of prevalence and correlates of suicidal ideation and suicide attempts among prisoners in New South Wales, Australia. BMC Public Health, 12, 14. 
RUNNING HEAD: Suicide ideation amongst people referred in police custody

Marzano, L., Fazel, S., Rivlin, A., \& Hawton, K. (2011). Near-lethal self-harm in women prisoners: contributing factors and psychological processes. The Journal of Forensic Psychiatry and Psychology, 22, 6, 863 - 884.

McKenzie, J., Borrill, J., \& Dewart, H. (2013). Researching suicide, attempted suicide and nearlethal self-harm by offenders in community settings: challenges for future research. International Journal of Forensic Mental Health, 12(1), 26-32.

McKinnon, I., \& Grubin, D. (2010). Health screening in police custody. Journal of Forensic and Legal Medicine, 17(4), 209-212.

McKinnon, I. G., \& Grubin, D. (2013). Health screening of people in police custody-evaluation of current police screening procedures in London, UK. The European Journal of Public Health, 23(3), 399-405.

McKinnon, I.G., \& Grubin, D. (2014). Evidence-based risk assessment screening in police custody: the HELP-PC study in London, UK. Policing, 8(2), 174-182.

McKinnon, I., Srivastava, S., Kaler, G., \& Grubin, D. (2013). Screening for psychiatric morbidity in police custody: results from the HELP-PC project. The Psychiatrist, 37, 389-394.

Ministry of Justice. (2013). Management of prisoners at risk of harm to self, to others and from others (Safer Custody): PSI 64/2011. London: Ministry of Justice.

Ministry of Justice. (2013). Transforming Rehabilitation: a Strategy for Reform. London: Ministry of Justice.

National Appropriate Adult Network. (2013). NAAN National Standards. Available at: http://www.appropriateadult.org.uk/images/pdf/national standards 2013.pdf - Accessed on 5th April 2016.

Noga, H. L., Walsh, E. C., Shaw, J. J., \& Senior, J. (2015). The development of a mental health screening tool and referral pathway for police custody. The European Journal of Public Health, 25(2), 237-242.

Noga, H., Foreman, A., Walsh, E., Shaw, J., \& Senior, J. (2015). Multi-agency action learning: Challenging institutional barriers in policing and mental health services. Action Research, 1476750315583315.

Oake-Rogers, S., \& Slade, K. (2015). Rethinking pathways to completed suicide by female prisoners. The Journal of Mental Health Training, Education and Practice, 10(4), 245-255.

Office of National Statistics. (2015). Statistical Bulletin: Suicides in the United Kingdom 2013 registrations. London: Office of National Statistics.

Payne-James, J. J., Green, P. G., Green, N., McLachlan, G. M. C., Munro, M. H. W. M., \& Moore, T. C. B. (2010). Healthcare issues of detainees in police custody in London, UK. Journal of Forensic and Legal Medicine, 17(1), 11-17.

Pratt, D., Appleby, L., Piper, M., Webb, R., \& Shaw, J. (2010). Suicide in recently released prisoners: a case-control study. Psychological Medicine, 40(05), 827-835.

Pratt, D., Piper, M., Appleby, L., Webb, R., \& Shaw, J. (2006). Suicide in recently released prisoners: a population-based cohort study. The Lancet, 368(9530), 119-123.

Prisons and Probation Ombudsman for England and Wales. (2014). Risk factors in self-inflicted deaths in prisons. London: Prisons and Probation Ombudsman. 
RUNNING HEAD: Suicide ideation amongst people referred in police custody

Rivlin, A., Fazel, S., Marzano, L., \& Hawton, K. (2013). The suicidal process in male prisoners making near-lethal suicide attempts. Psychology, Crime and Law, 19(4), 305 - 327.

Roberts, A., Senior, J., Hayes, A., Stevenson, C., \& Shaw, J. (2011). An independent evaluation of the Department of Health's procedure for the transfer of prisoners to hospital under the Mental Health Act 1983. The Journal of Forensic Psychiatry and Psychology, 23(2), 217-236.

Samaritans. (2015). Suicide Statistics Report 2015. London: Samaritans.

Sattar, G. (2001). Rates and causes of death among prisoners and offenders under community supervision. London: Home Office Research Study 231.

Scott, D., McGilloway, S., \& Donnelly, M. (2009). The mental health needs of women detained in police custody. Journal of Mental Health, 18(2), 144-151.

Slade, K., \& Forrester, A. (2015). Shifting the paradigm of prison suicide prevention through enhanced multi-agency integration and cultural change. The Journal of Forensic Psychiatry \& Psychology, 26(6), 737-758.

Srivastava, S., Forrester, A., Davies, S., \& Nadkarni, R., (2013). Developing criminal justice liaison and diversion services: research priorities and international learning. Criminal Behaviour and Mental Health, 23(5), 315-320.

Till, A., Exworthy, T., \& Forrester, A. (2015). Integration and offender mental health. The Journal of Forensic Psychiatry \& Psychology, 26(1), 11-21.

Zalsman, G., Hawton, K., Wasserman, D., van Heeringen, K., Arensman, E., Sarchiapone, M., Carli, V., Hoschl, C., Barzilay, R., Balazs, J., Purebl, G., Kahn, J., Saiz, P., Lipsicas, C., Bobes, J., Cozman, D., Hegerl, U., \& Zohar, J. (2016). Suicide prevention strategies revisited: 10-year systematic review. The Lancet Psychiatry. 


\section{Tables}

Table 1: Ethnic categories for arrestees by suicide ideation sub-groups, and English not as first language

\begin{tabular}{|c|c|c|c|c|c|}
\hline & $\begin{array}{l}\text { Suicide ideation } \\
(N=144)\end{array}$ & $\begin{array}{l}\text { No suicide } \\
\text { ideation } \\
(\mathrm{N}=744)\end{array}$ & & & \\
\hline Broad ethnic Group & Number (\%) & Number (\%) & Chi2 & $p$-value & $95 \% \mathrm{Cl}$ of difference \\
\hline White & 75 (52.1) & $342(46)$ & 1.77 & .107 & $-3.2-15.4$ \\
\hline Black & $52(36.1)$ & $274(36.9)$ & .03 & .47 & $-9.7-8.3$ \\
\hline Asian & $3(2.1)$ & $22(3)$ & .339 & .401 & $-3.9-2.2$ \\
\hline Mixed & $8(5.6)$ & $85(11.4)$ & 4.45 & $.02 *$ & $-10.7--1.1$ \\
\hline Chinese & $2(1.4)$ & $5(0.7)$ & .79 & .318 & $-1.7-3.1$ \\
\hline Other & $4(2.8)$ & $15(2)$ & .331 & .373 & $-2.5-4.0$ \\
\hline $\begin{array}{c}\text { English is not first } \\
\text { language }\end{array}$ & $24(16.7)$ & $188(25.3)$ & 4.91 & $.015^{*}$ & $-15.8--1.3$ \\
\hline
\end{tabular}


Page 17 of 20

Journal of Criminal Psychology

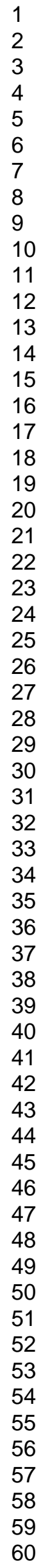


Table 2: Frequency and chi-square analysis of difference between arrestees with suicide ideation

\begin{tabular}{|c|c|c|c|c|c|}
\hline Variable & $\begin{array}{l}\text { Suicide } \\
\text { Ideation } \\
N=144(\%)\end{array}$ & $\begin{array}{l}\text { No current } \\
\text { suicide } \\
\text { ideation } \\
\mathrm{N}=744(\%)\end{array}$ & $\mathrm{Chi}^{2}$ & p-value & $\begin{array}{l}95 \% \mathrm{Cl} \text { of } \\
\text { difference }\end{array}$ \\
\hline \multicolumn{6}{|l|}{ Previous history } \\
\hline $\begin{array}{l}\text { Previous self-harm or suicide } \\
\text { attempt }\end{array}$ & $115(79.9)$ & $393(52.8)$ & 36.03 & $<.001 * *$ & $19.2-34.9$ \\
\hline Previously known to $\mathrm{MH}$ services & $110(76.9)$ & $486(65.3)$ & 5.52 & $.011^{*}$ & $2.9-19.2$ \\
\hline Previous Mental Disorder & $136(94.4)$ & $605(81.3)$ & 15.05 & $<.001 * *$ & $8.0-18.2$ \\
\hline Previous medication & $88(68.1)$ & $393(52.8)$ & 3.34 & $.041^{*}$ & $-0.8-17.4$ \\
\hline Previous admission to hospital & $65(58.6)$ & $315(42.3)$ & 1.46 & .136 & $-6.5-12.1$ \\
\hline \multicolumn{6}{|l|}{ Current substance use } \\
\hline Alcohol or Drug Use in last 24 hours & $84(58.3)$ & 334 (44.9) & 4.63 & $.019 *$ & $4.2-22.6$ \\
\hline Current alcohol use & $84(58.3)$ & $367(49.3)$ & 3.91 & $.029 *$ & $0.2-18.2$ \\
\hline Current cannabis use & $14(9.7)$ & $83(11.2)$ & .255 & .369 & $-7.2-4.3$ \\
\hline \multicolumn{6}{|l|}{ Offence charge } \\
\hline Violence offence & $41(28.5)$ & $220(29.6)$ & .070 & .438 & $-9.6-7.4$ \\
\hline Sexual offence & $32(22.2)$ & $155(20.8)$ & .140 & .391 & $-6.4-9.2$ \\
\hline Drugs offence & $37(25.7)$ & $171(23)$ & .494 & .273 & $-5.5-10.9$ \\
\hline Arson offence & $5(3.5)$ & $50(6.7)$ & 2.19 & .093 & $-7.1-0$ \\
\hline Fraud offence & $15(10.4)$ & $70(9.4)$ & .142 & .40 & $-4.8-6.8$ \\
\hline Threat offence & $11(7.6)$ & $58(7.8)$ & .004 & .555 & $-5.0-4.7$ \\
\hline
\end{tabular}


Previous criminal record

On bail when arrested

Previous violent convictions

Service response

Not fit for interview

$29(21.2)$

Seen by Operation Emerald Worker 52 (36.6)

Seen by arrest referral worker

28 (19.9)

Seen by forensic medical examiner 30 (21.3)

Seen by any health professional

\section{Diagnostic and Clinical}

Schizophrenia/Psychosis

Substance Use Disorder

Depression

PTSD

Personality Disorder

Intellectual Disability
$22(15.3)$

47 (32.6)

$72(50)$

22 (15.3)

$29(20.1)$

11 (11.8)

\author{
613 (82.4)
}

$110(15.3)$

407 (54.7)
.523

$4.11 \quad .032 * \quad-1.5-13.6$

.035

.462

$-8.4-10.1$

35

37

38

39

40

41

42

43

44

45

46

47

48

49

50

51

52

53

54

55

56

57

58

59

60 
Journal of Criminal Psychology

Page 20 of 20

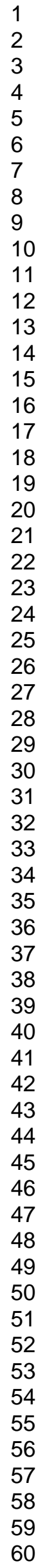

